\title{
Engineering Multiphysics Research
}

\author{
doi:10.3991/ijoe.v7i2.1641 \\ Ivana Milanovic, Tom A. Eppes, and Ingrid Russell \\ University of Hartford, West Hartford, CT, USA
}

\begin{abstract}
This paper describes an engineering undergraduate course that covers the methods and techniques of multiphysics modeling. Students become active participants in analysis and discovery by being challenged to solve a sequence of problems related to high priority technology areas. Projects range from power systems and thermal control of habitats to autonomous flight systems and harsh environment electronics. Working in a cooperative learning environment, teams encounter a series of assignments that build on existing skills while gradually expanding their knowledge and expertise in disciplines outside of their own. This project-based approach employs a scaffolding structure with assignments organized in progressively challenging modules supported by mentoring.
\end{abstract}

Each project begins with a problem definition which requires consideration of factors and influences beyond a single discipline. Solution development then moves to setting material properties, boundary constraints and including the necessary physics engines. For many students, this is the first in depth exposure to problems with specialized terminologies, driving equations and limiting conditions. Lastly, solving and post processing are addressed exploring steady state, time-variant, frequency response, optimization and sensitivity methods. The paper discusses the teaching and learning strategies, course structure, outcome assessment and project examples.

Index Terms-multiphysics modeling, multidisciplinary design, contextual projects.

\section{INTRODUCTION}

The authors teach in an institution where approximately 400 undergraduate students major in engineering. Bachelor of Science degrees are offered in six degree programs: Acoustical Engineering \& Music, Biomedical, Civil, Computer, Electrical and Mechanical Engineering. The College also has a Masters of Engineering program with about 150 students.

Engineering graduates are facing an emerging class of design challenges that span multiple disciplines of science and technology. Sophisticated computational techniques, combining the representative physics of multiple domains, are needed to accurately model and predict results. Most engineering degree programs offer major specific modeling courses or embed simulations on a limited basis. For example, mechanical undergraduates may be exposed to solid modeling and computational fluid dynamics while electrical majors apply finite element techniques to electromagnetic problems. Few engineering curricula, including those in our College, offer multiphysics design and research experiences. Where available, they are typically restricted to post-graduate studies; consequently, most baccalaureate graduates receive little or no exposure to areas of expertise outside their own discipline. This is inconsistent with the view that future graduates need to be more adaptable and versatile to succeed in the global marketplace [1].

The authors have developed an engineering undergraduate course focused on the methods and techniques used in multidisciplinary modeling. Students become active participants by being challenged to solve a series of projects. Contextualized assignments are selected from high priority research topics ranging from power systems and thermal control of habitats to autonomous flight vehicles and harsh environment electronics. Studies have shown that the choice of context or problem domain can have a dramatic impact on student motivation and in turn on the quality of learning [2-4]. A problem domain that a student relates to and finds relevant leads to deeper understanding and a smoother transfer to other domains. Contextualized projects lead to a more enjoyable experience motivating students to work in a new way.

Set in a cooperative learning environment, teams encounter a series of projects that build on existing skills while gradually expanding their knowledge and expertise in disciplines outside their own. This project-based approach employs a scaffolding structure in which assignments are organized into three sets of progressively challenging modules [5]. In this sense, scaffolding is linked to the learning theories of Vygotsky [6-7] in which a learner's cognitive development is enabled by interaction with more capable members of the same culture - usually teachers or other students [8]. Upon encountering difficulty, the learner gets appropriate assistance that enables a breakthrough. Scaffolding is the act of providing those facts currently needed by a learner but unknown to that learner. An important implication of Vygotsky's theory is that assistance be removed once it is no longer required.

\section{MultiPhySiCs MODELING}

To be successful in a knowledge-based global workplace, an engineering graduate should have the ability to design complex systems of devices and components that perform in real-world conditions. In such problems, multiple sets of coupled physics often apply and interact in both space and time. A robust model must therefore span several disciplines to obtain a solution that can be experimentally validated.

One approach is to use numerical techniques in which the physical geometry is represented by a mesh of finite elements that collectively satisfy the relevant equations. To simplify development, the preferred approach is to employ a single solution builder to configure, constrain, solve and post-process results. At times, multiple models, each with specific geometry, materials, constraints and physics may be used sequentially or co-exist and be coupled. As with all numerical methods, care must be taken to 
ensure proper convergence and accuracy of the end result. Model creation typically proceeds along these lines:

- Define problem including simplifying assumptions

- Identify global constants and expressions

- Construct physical geometry including symmetries

- Specify domains and material properties

- Set boundary conditions

- Mesh physical structure into finite elements

- Select physics for each domain

- Configure study types and initiate solver

- Post-process results

Multiphysics software (e.g. COMSOL or ANSYS) can accelerate the timetable needed to create a working model. A family of graphical interfaces, organized in a tree structure, guides the development process while providing contextual help along the way. Geometries can be imported from leading computer-aided-drawing (CAD) packages. A properties library is embedded that covers many common materials. Meshing options include external file import and adaptive where dynamic adjustments are made during the solving process. An interface to MatLab permits access to m-file algorithms. Energy sources and forcing functions may contain time and space relationships as well as other constraints that are functions of the dependent variables themselves. If necessary, users customize the physics further by adding additional algebraic expressions and partial differential equations.

\section{COURSE STRUCTURE}

The course is 3 credits and transpires over a 15 week semester. It is offered to all engineering majors with a senior standing. It is taught in a computer laboratory with a maximum of 16 . All students, upon entering the course, will have covered the following topics in prior semesters: multivariate differential equations, theory of electrical and electronic circuits, and dynamics. Knowledge of numerical methods is not required; however, many students have taken such a course as part of a minor in mathematics.

The teaching and learning strategies were developed by the authors who have advanced degrees in the disciplines of electrical engineering, mechanical engineering, and computer science. The following types of co-teaching are envisioned: lead and support, team, and alternative. The course is currently being taught by one instructor at a time, but other options are being explored.

We now describe the course and student organizational context. In the authors' experience, too often experiential courses are overly reliant on assignments with predetermined results. Students are tasked to complete and document work where only correct and predictable outcomes are allowed. This approach is an unimaginative one and denies students the opportunity to build models from scratch, experience difficulties, be resourceful and explore different avenues while making decisions along the way [5].

The course design is based on four teaching and learning strategies:

1. Cooperative learning in teams of two

2. Scaffolding that builds competency in multidisciplinary modeling
3. Contextualized by focusing on relevant topics

4. Project-based assignments

The first strategy involves cooperative learning in which students work in teams of two. Whenever possible, students from different majors are paired. Prior research in skill development by Culver et al. [9] and King et al. [10] showed that students mature most readily when teaching balances both challenge and support. Challenge incorporates repeated exposure to and synthesis of the legitimate uncertainties in knowledge and is supported by high quality mentoring. Student-centered teaching that includes a rich combination of active and cooperative learning is advocated by Felder et al. [11-12].

Millis and Cottell [13] offer thorough and welldocumented support for cooperative learning at the college level provided that students are trained. While in most courses there is insufficient time for training [14], by keeping the team members and assessment materials the same, students learn to effectively perform peer and self evaluation [5].

With respect to the second strategy, assignments and instructor mentoring are integrated using a scaffolding technique patterned after previous curricular work by the authors [5]. The inclusion of scaffolding techniques has been widely reported in computer programming courses by Saunders, Mullins and Panitz [15-17]. Jackman et al. [18] applied scaffolding to the formulation stage for illstructured problems in an Engineering Economy course that included students from multiple engineering disciplines. In Jackman's [18] approach, the instructor or learning system supplants the student's ability to perform some part of the task by adjusting the nature or difficulty of the task. Working through series of assignments that progressively build on existing skills, students expand their interdisciplinary knowledge and expertise.

The third strategy heightens motivation by selecting topics from high priority research areas. Interest is peaked as students become active participants in analysis and discovery of relevant and important design problems.

The fourth strategy is to use project-based assignments, each containing a high level of hands-on activity. Assignments are organized into three modules: (1) classical projects with prescribed outcomes, (2) higher level transitional projects, and (3) a student-centric design of a model. This structure builds on existing skills and knowledge, connects them in a logical way and engages students in inquiry and learning, gradually developing competence.

Module 1: Classical projects familiarize students with the process of multiphysics modeling and the user interfaces of the software application. Teams following a set of procedures, construct working models, analyze results and write formal reports. The learning outcomes associated with Module 1 are to:

- Gain familiarity with modeling development process

- Learn the graphical user interface

- Complete a modeling project from scratch

- Document the results in a technical report

Module 2: Transitional projects have defined objectives; however, some design elements are intentionally left out prompting students to synthesize a working model so that meaningful results can be acquired. Although the goal 
is clearly stated, the task of filling in the missing pieces is the challenge. The learning outcomes of Module 2 are to:

- Discover missing modeling elements

- Research and incorporate relevant information

- Synthesize a successful project

- Justify, validate, and document the results

Module 3: Design of a model (DoM) is the culminating experience in which the students are required to integrate prior skills into an independent research initiative appropriate for the course. Each team must propose, plan and execute a design based on a proposal that is relevant to the course topics and suitable in rigor. At an end-of-thesemester event, each team delivers a formal oral presentation to a group of judges made up of faculty, alumni and an outside panel, some of whom are practicing engineers drawn from local industry. The learning outcomes of Module 3 are to:

- Generate concepts and filter down to a single proposal

- Research and utilize relevant information

- Evaluate alternatives within the construct of the model

- Synthesize a design and generate a solution

- Manage the project within time constraints

- Formally document the findings

- Deliver a formal oral presentation

In summary, the course integrates four teaching and learning strategies in an innovative way. Project-based assignments, focused on relevant research topics, are delivered using a scaffolding process and conducted in a cooperative learning environment.

\section{OUTCOME ASSESSMENT}

This section discusses the five skills areas that are assessed. For all three modules, two rubrics (technical reports and teams skills) are employed. Table I shows how each rubric is used to measure skill level. Technical reports are submitted following each assignment after which feedback is provided. Students are expected to correct mistakes and improve the quality of work. The skill areas of written communication, teamwork and modeling proficiency rely on input from the technical reports rubric. Students perform peer and self assessment using a team skills rubric that measure four attributes: Research and Gather Information, Fulfill Team Role's Duties, Share Equally and Listens to Other Teammates. Qualitative feedback is solicited in the form of commentary.

The DoM module requires considerably more work compared to the first two modules and takes place over the final five weeks of the semester. In addition to technical reports and team skills, two additional rubrics (status reports and oral presentation) are used with the DoM as shown in Table II.

Teams submit weekly status reports that address: tasks and accomplishments, problems encountered and approach to solution, changes to objectives, future activities, needed support, and schedule concerns. Status reports are not graded or formally assessed; however, at the discretion of the instructor, individuals and/or team(s) may be sanctioned and/or penalized for failure to report progress on a timely basis.
TABLE I.

ASSESSMENT RUBRICS AND SKILL AREAS

\begin{tabular}{|ll|c|c|}
\hline \multirow{2}{*}{\multicolumn{2}{|c|}{ Skill Area }} & \multicolumn{2}{c|}{$\begin{array}{c}\text { Rubrics for } \\
\text { All modules }\end{array}$} \\
\cline { 3 - 4 } & \multicolumn{2}{c|}{$\begin{array}{c}\text { Technical } \\
\text { Reports }\end{array}$} & $\begin{array}{c}\text { Team } \\
\text { Skills }\end{array}$ \\
\hline 1. & Written Communication & $\checkmark$ & \\
\hline 2. & Teamwork & $\checkmark$ & $\checkmark$ \\
\hline 3. & Modeling Proficiency & $\checkmark$ & \\
\hline 4. & Information Literacy & $\checkmark$ & \\
\hline
\end{tabular}

TABLE II.

DOM ASSESSMENT RUBRICS AND SKILL AREAS

\begin{tabular}{|ll|c|c|}
\hline \multirow{2}{*}{ Skill Area } & \multicolumn{2}{|c|}{$\begin{array}{c}\text { Rubrics for } \\
\text { Module 3: DoM only }\end{array}$} \\
\cline { 3 - 4 } & $\begin{array}{c}\text { Status } \\
\text { Reports }\end{array}$ & $\begin{array}{c}\text { Oral Presenta- } \\
\text { tion }\end{array}$ \\
\hline 1. $\quad$ Written Communication & $\checkmark$ & \\
\hline 2. $\quad$ Teamwork & $\checkmark$ & \\
\hline 3. $\quad$ Modeling Proficiency & $\checkmark$ & $\checkmark$ \\
\hline 5. $\quad$ Oral Communication & & $\checkmark$ \\
\hline
\end{tabular}

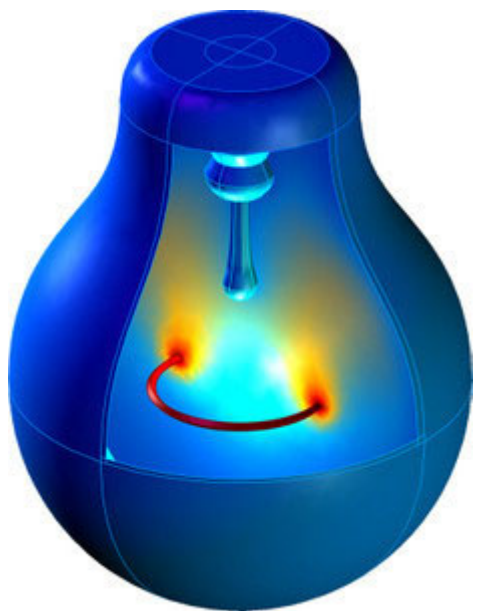

Figure 1. Filament heated light bult [19]

At the end of the semester, a formal DoM oral presentation is given to a panel of evaluators where communication and modeling skills are assessed on a scale of 1 to 4 . The oral communication rubric is based on rhetorical concepts emphasized in previous technical writing courses: appropriate for audience, organization, graphics, English conventions and delivery. A specialized project modeling rubric evaluates the following skills: problem definition, relevant background information gathered, working solution and quality of post-processed results.

\section{PROJECT EXAMPLES}

In this section, one sample project is presented from each module. The first module, Classical, includes an incandescent light bulb illustrated in Fig. 1 [19]. The light bulb contains a tungsten filament that is resistively heated when a current is passed through it. At temperatures around $2000 \mathrm{~K}$, the filament starts to emit visible light. To prevent the tungsten wire from burning up, the bulb is filled with a gas, usually argon. 
Heat generated in the filament is transported to the surroundings through radiation, convection, and conduction. As the gas heats up, density and pressure changes induce a flow field inside the bulb. The heating process has a long and a short time scale after the light is turned on. The short scale captures the heating of the filament and the gas close to it. Temperature-induced density changes in the argon lead to a convective flow inside the bulb. On a longer time scale, the glass on the bulb's outer side heats up.

As with all classical projects, teams are provided stepby-step instructions on how to create a working model and visualize the results. In this case, the model predicts the following parameters: (1) temperature distribution and (2) velocity fields of the argon gas after several minutes of operation. Figure 2 depicts the temperature distribution after 5 minutes of operation [19].

The next project is Transitional and involves a power transistor mounted on a printed circuit board using through-hole technology [20]. The solder in the holes give mechanical support and electronic contact between the copper routes and the transistor pins. Current conduction and Joule heating take place in the copper routes, solder joints, and pin-outs. In these parts, the physics of heat transfer and heat production due to Joule heating are fully coupled to the conduction of electric current. In all other parts of the transistor, only heat transfer and heat production take place.

The objective is to determine if the steady state temperature is below an acceptable maximum for a given power level. In transitional projects, teams are NOT provided step-by-step instructions on how to build the model. In addition, some material properties and boundary conditions are left out, forcing students to research appropriate values and conditions. The resulting temperature distribution for a power level 1 Watt is shown in Fig. 3 [20].

The final sample project illustrates a DoM based on a two-phase model of laser percussion drilling, a thermal, contact-free process that utilizes a focused optical beam to remove material by vaporization and melt ejection. This process is used in the aerospace industry to produce cooling holes in jet engine components [21]. Figure 4 shows how air flow along interior serpentine channels feeds an array of holes providing a thin cooling film that protects the blade from high combustion gas temperatures [22].

The objectives of this particular DoM as set forth by the student team is to:

- Use iron as the target material and show the twodimensional temperature profile as a function of time for a single optical pulse

- Identify the location of the solid-to-liquid interface within the target over time

- Compare and contrast the above results for different optical power levels, pulse shapes, angles of incidence, and polarizations

The model contains an ensemble of equations that collectively describe the physics of the process. Temperaturedependent material properties, such as specific heat to preserve enthalpy, are used to track phase transformation from solid to liquid. The model is capable of generating results for any angle of incidence, two different beam profiles (Gaussian and flat-top) as well as polarization (normal or parallel to the surface).

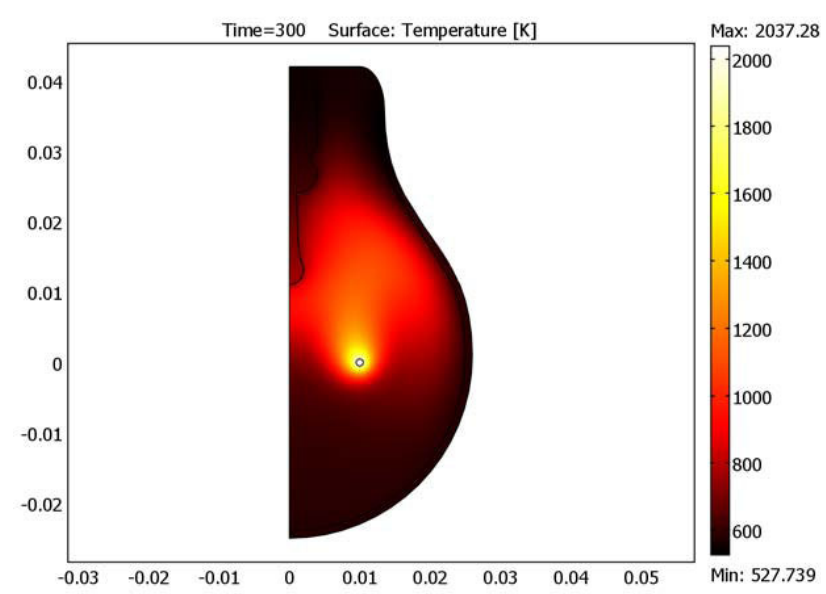

Figure 2. Temperature distribution after 5 minutes [19]

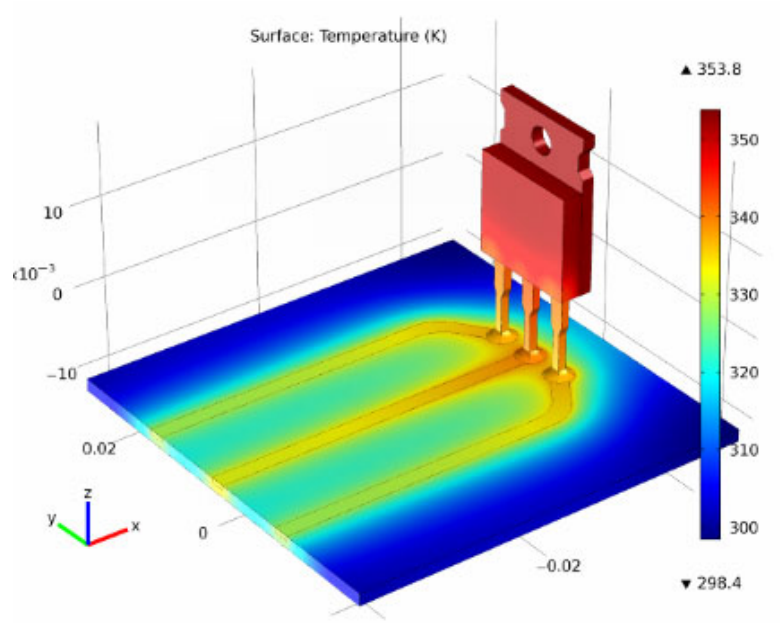

Figure 3. Power transistor temperature distribution [20]

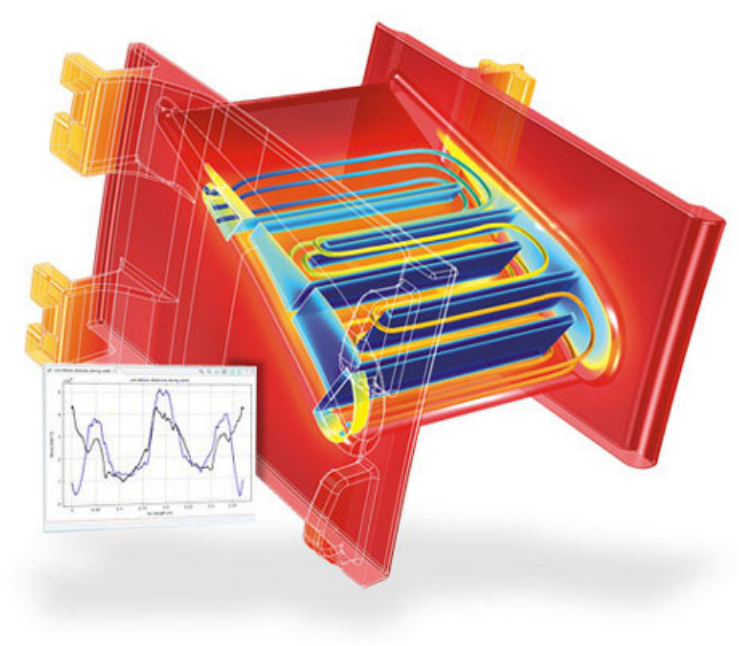

Figure 4. Air flow inside a turbine blade [22]

A two-dimensional meshed geometry with a flat planar surface represents the target with an optical beam incident on the surface. Based on the angle of incidence and polarization, some fraction of the optical energy is absorbed. Over time, the temperature inside the target increases as heat is conducted into its interior. Temperature fields re- 
PAPER

ENGINEERING MULTIPHYSICS RESEARCH

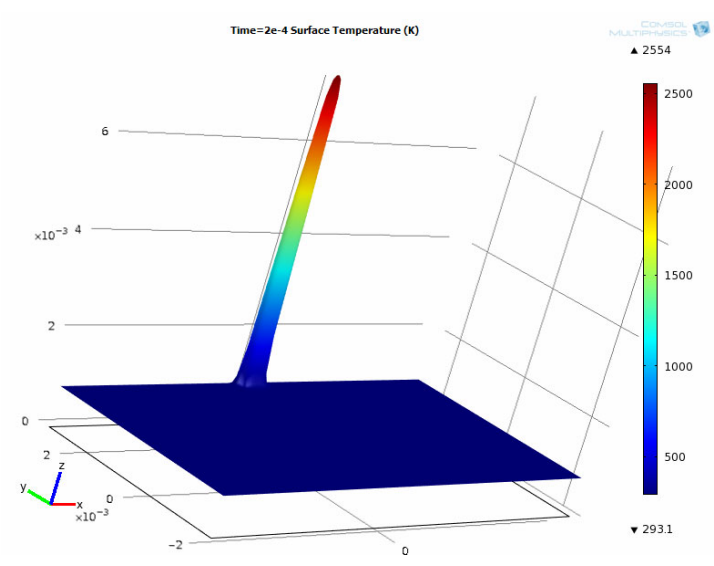

Figure 5. Temperature distribution in target material

veal the shape, speed and depth of heat transfer over time. After sufficient energy absorption, the model generates a temperature distribution over time as shown in Fig. 5.

\section{CONCLUSION}

This paper describes an engineering undergraduate course that covers the methods and techniques involved in multiphysics modeling. Students become active participants in analysis and discovery by being challenged to solve a sequence of high priority technology problems. Examples of projects range from power systems and thermal control of habitats to autonomous flight systems and harsh environment electronics. Working in a cooperative learning environment, teams encounter a series of relevant projects that build on existing skills while gradually expanding their knowledge and expertise in disciplines outside of their own. Four teaching and learning strategies are integrated into the course: (1) cooperative learning teams, (2) relevant topics, (3) project-based assignments, and (4) scaffolding organized in progressively challenging modules.

Each project begins with a problem definition which requires consideration of factors and influences beyond a single discipline. Solution development then moves to setting material properties, boundary constraints and the necessary physics engines. For many students, exposure to new phenomena with specialized terminologies, driving equations and limiting conditions is a first-time experience. Lastly, solving and post processing are addressed exploring steady state, time-variant, frequency response, optimization and sensitivity methods.

\section{REFERENCES}

[1] Friedman, T. L., The World is Flat: A Brief History of the Twenty-First Century, Farrar, Straus, and Giroux, 2005.

[2] Guzdial, M., "Contextualized Computing Education: Increasing Retention by Making Computing Relevant", White paper, Georgia Institute of Technology, 2007.

[3] Russell, I., Markov, Z., Neller, T. and Coleman, S., "MLeXAI: A Project-Based Application-Oriented Model", The ACM Transactions on Computing Education, 10(3), 2010.
[4] Russell, I., Markov, Z., Coleman, S., "Project MLExAI: Applying Machine Learning to Web Document Classification", Journal of Computing Sciences in Colleges, 23(2), 2007.

[5] Milanovic, I., Eppes, T. and Sweitzer, F., "Progressive Curricular Structure for STEM Programs," Int'l J. of Arts and Sciences, 3(14), 2009, 118-126.

[6] Vygotsky, L.S., Thought and Language, Cambridge, MA, MIT Press, 1962. doi:10.1037/11193-000

[7] Vygotsky, L.S., Mind in Society, Cambridge, MA, Harvard University Press, 1978.

[8] Sticklen, J., Amey, M., Eskil, T., Hinds, T. and Urban-Lurain, M., "Application of Object-Centered Scaffolding to Introductory MatLab," ASEE Conference Proceedings, 2004, Salt Lake City, UT.

[9] Culver, R. S., Woods, D., Fitch, P., "Gaining Professional Expertise Through Design Activities," J. Engr. Education, 80, 533-536, 1990.

[10] King, P. M. and Kitchner, K. S., Developing Reflective Judgment, Jossey-Bass Publishers, San Franciso, 1994.

[11] Felder, R. M., and Brent, R., "Learning by Doing," Chem. Engr. Education, 37 (4), 282-283, 2003.

[12] Felder, R. M., and Brent, R., "The Intellectual Development of Science and Engineering Students. Part 1. Models and Challenges," J. Engr. Education, 93 (4), 269-277, 2004.

[13] Millis, B. J., and Cottell, P., Cooperative Learning for Higher Education Faculty. Phoenix: American Council on Education and Oryx Press, 1998.

[14] Chapman, C., A Good Idea.But It Might Not Work, The NEA Higher Education J. Thought \& Action, 135-136, 1998.

[15] Saunders, J., Nehaniv, C. and Dautenhahn, K., "Teaching Robots by Moulding Behavior and Scaffolding the Environment," Proceedings of the $1^{\text {st }}$ ACM SIGITE/SIGART Conference on HumanRobot Interaction, 2006. doi:10.1145/1121241.1121263

[16] Mullins, P.M. and Conlon, M., "Engaging Students in Programming Fundamentals Using Alice 2.0," Proceedings of the $9^{\text {th }}$ ACM-SIGITE Conference on Information Technology Education, pages 81-88, 2008, New York, NY. doi:10.1145/1414558.1414584

[17] Panitz, M., Sung, K. and Rosenberg, R., "Game Programming in CS0: A Scaffolded Approach," J. of Computing Science in Colleges, 26(1), 2010.

[18] Jackman, J., Ryan, S., Ogilvie, C. and Niederhauser, D., "Scaffolding to Improve Reasoning Skills in Problem Formulation," ASEE Conference Proceedings, 2008, Pittsburgh, PA.

[19] "Free convection in a light bulb" [online], accessed 10/31/2010, http://comsol.com/showroom/documentation/model/303.

[20] "Heat distribution in a power transistor" [online], accessed 10/31/2010, http://comsol.com/showroom/documentation/model/ $\underline{8577}$.

[21] Eppes, T. A., Milanovic, I. M., Shetty, D., "Laser Percussion Drilling Modeling Utility," J. of Laser Applications, 21(2), 102109, 2009. doi:10.2351/1.3120192

[22] "Air flow in a staor turbine blade," [online], accessed 10/31/2010, http://comsol.com/press/gallery/?filter=comsol+multiphysics $+4.0+$ images.

\section{AUTHORS}

Ivana Milanovic, Tom A. Eppes, and Ingrid Russell are with University of Hartford, West Hartford, CT, USA.

This article is an extended version of a paper presented at the IEEE EDUCON20211 Conference, held from April 4th-6th, 2011, in Amman, Jordan. Received April $20^{\text {th }}, 2011$. Published as resubmitted by the authors May $2^{\text {nd }}, 2011$. 